\title{
Research on the Glass Silicon Anodic Direct Bonding Parameters
}

\author{
Li Jia*1, Guo Hao ${ }^{2}$, Guo Zhiping ${ }^{3}$, Miao Shujing ${ }^{4}$, \\ ${ }^{1}$ Mechanical Engineering Institute of Inner Mongolia University of Technology, China \\ ${ }^{2}$ Robotics and Microsystems Center, Soochow University China \\ ${ }^{3,4}$ Mechanical Engineering Institute of Inner Mongolia University of Technology, China \\ *Corresponding author, e-mail: 121011707@qq.com', hguo@suda.edu.cn², guozhp@imut.edu.cn ${ }^{3}$
}

\begin{abstract}
By MEMS packaging test platform for bonding process of bonding temperature and bonding time, and test silicon specifications experimental study. Firstly, according to the anodic bonding principle, the main factors to determine the effect of bonding quality. Secondly, change the bonding temperature, bonding time, and test wafer size and other parameters, glass silicon bonding contrast test. Finally, the calculation and analysis of comparative test of each group is bonded porosity, summarized the factors that affect the quality of the bonding and bonding to achieve the best results in the bonding conditions. Experimental results indicate that when the bonding voltage of $1200 \mathrm{~V}$, bonding temperature of $445^{\circ} \mathrm{C}$ to $455^{\circ} \mathrm{C}$, bonding time is $60 \mathrm{~s}$, the void fraction is less than $5 \%$. Glass and silicon wafer bonding quality can achieve the best. The experimental results in order to improve the glass silicon bonding quality provide the basis.
\end{abstract}

Keywords: Glass-Si bonding, MEMS, encapsulation, void fraction

Copyright $(2015$ Institute of Advanced Engineering and Science. All rights reserved.

\section{Introduction}

MEMS (Micro Electro Mechanical System) is a micro mechanical elements, microsensors, micro-actuators, signal processing and control circuit integrated in one of the micro system.Direct bonding technology is between two wafers without an intermediate layer, using anodic bonding manner directly bonded [1]. Silicon and glass is the most commonly used material is directly bonded with a low reaction temperature and high bonding strength advantages. Glass and silicon direct anodic bonding is an important step in the process of micro sensor package. Package quality affects directly the performance and the reliability of the sensor.

Void fraction is one of the important parameters to characterize the glass silicon anodic bonding quality. The definition of void ratio: Empty area did not occur bonded percentage of the total area of the wafer on test interface. The expression as:

$$
V_{\mathrm{w}}=S_{V} / S_{W}
$$

In the expression, $V_{\mathrm{m}}$ is Void fraction. $S_{\mathrm{v}}$ is the total area of voids, $S_{W}$ is The total area of silicon.

There are many main factors that influence the anodic bonding quality. Generally believe that, Bonding temperature controlled at $300-500^{\circ} \mathrm{C}$ more appropriate. In this temperature range, the conductivity of the sodium ions have sufficient migration rate. More than $500^{\circ} \mathrm{C}$, it will result in a silicon microelectronic process certain materials (such as aluminum) failure and incompatibility with other micromachining. The recommended applying a voltage is between $200 \mathrm{~V}-1200 \mathrm{~V}$ in general, the range is wide, depending on the specific glass material properties and the selected bond temperature to decide. With the increase of applied voltage, the migration rate of conductive ions increases, the time required to attain equilibrium is shortened, namely complete bonding time reduction. When the bonding temperature exceeds $300^{\circ} \mathrm{C}$, due to the thermal expansion coefficient of the glass and silicon will vary, the higher the temperature, 
the greater the change.while the bonding temperature is too high, not only cause large residual stress, resulting in the glass itself burst, seriously affect the rate of bond synthetic products, thereby increasing its packaging costs, but also leads to the structure and properties of the existing parts is changed, and even to produce deformation, makes the bonding quality decreased.While the bonding temperature is too low, bonding strength and low efficiency step down, the bonding surface bubbles and voids are also difficult to reduce or eliminate. Therefore, the bonding temperature has a great influence on the quality of the bonding.Under the premise of quality assurance bond, lower bonding temperature is important.

\section{Test Program}

\subsection{Test Equipment}

MEMS package test platform is mainly used for packaging materials clean dry environment. The main structure shown in Figure 1, including the tray feeding mechanism; manipulator automated handling module; furnace combination; trays clamping motion mechanism; microscopy; Trays out of the feeding mechanism etc.

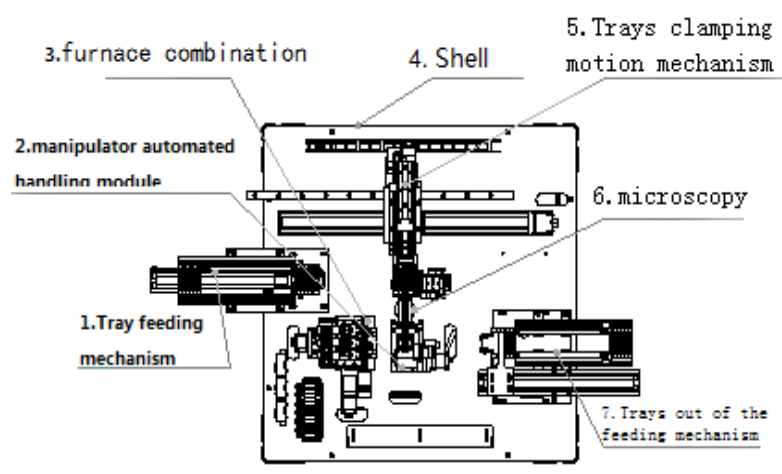

Figure 1. Structure diagram of MEMS package test

\subsection{Test material}

Basic performance BF33 glass excellent transparency, low fluorescence intensity and high ultraviolet and infrared transmittance.

1) Extremely low coefficient of expansion, thermal shock resistance and long-term working temperature up to $450^{\circ} \mathrm{C}$

2) Excellent chemical stability,have a high degree of corrosion resistance to water, acids, alkalis, and organic substances

Bonded article as a sample having a thickness of $0.5 \mathrm{~mm}$, a side length of $4 \mathrm{~mm}$, a resistivity of $0.01-1(\Omega \cdot \mathrm{cm})$ square silicon wafer and a thickness of $2 \mathrm{~mm}$, a diameter of $10 \mathrm{~mm}$ BF33 annular glass. Normal circumstances, the silicon wafer surface have oxide layer, and dust and other magazines, before bonding the silicon wafer and the glass must be cleaned with alcohol.

\subsection{Test Procedure}

MEMS package Test flowchart shown in Figure 3. 1) Start the software and initialize ;2) Press the "heating" button and wait for the heating to a predetermined temperature ; 3 ) put glass and silicon into the feed tray ;4) Click "Start", the system automatically starts the handling and bonding ;5) Observing the test results, Calculate the porosity. Complete test with different parameters. 


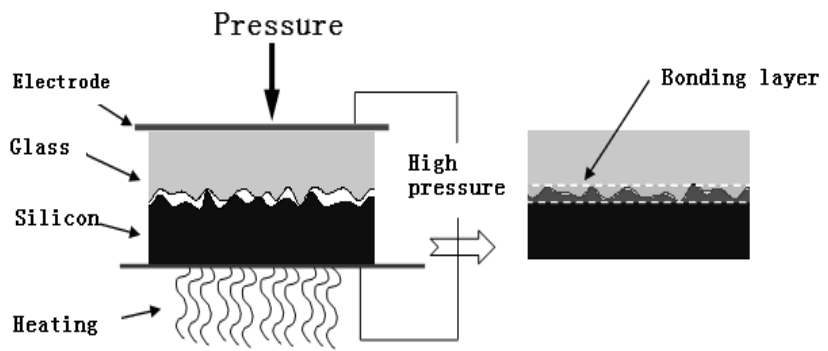

Figure 2. Schematic diagram of bonding principle

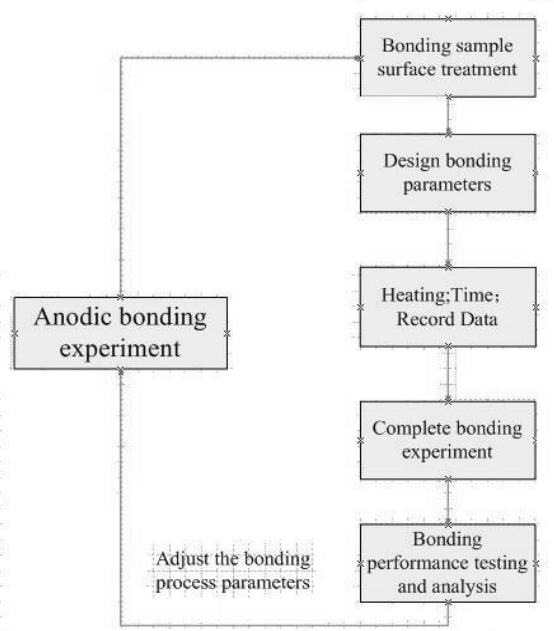

Figure 3. Fabrication process of MEMS package test

\section{Analysis of Test Results Test Program}

\subsection{Effect of Bonding Temperature on Bonding Current and Bonding Quality}

Glass wafer bonding temperature is generally chosen between $300-500^{\circ} \mathrm{C}$, and applied a DC high voltage(approximately $1000 \mathrm{~V}$ ). The range of heating temperature is large. In order to explore the optimal bonding temperature, setting this experiment bonding temperature is $395^{\circ} \mathrm{C}-$ $485^{\circ} \mathrm{C}$, and through the Hall sensor installed in the furnace, detected bonding temperature, voltage, current. After the bonding is completed, the glass and the wafer is separated, bonding conditions were observed with a microscope, and calculated the void fraction.

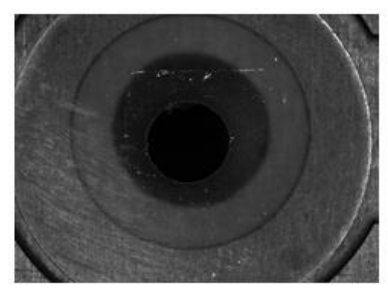

(a)

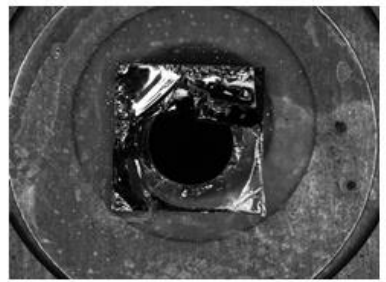

(c)

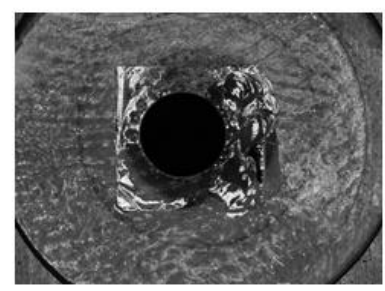

(b)

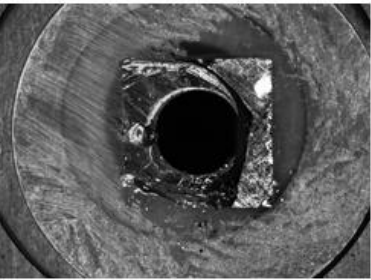

(d)

Figure 4. Microscope diagram of glass surface bonding 
Figure 4(a), (b), (c), (d) was observed by microscope bonding results for the bonding voltage $1200 \mathrm{~V}$, bonding temperatures of $395-405^{\circ} \mathrm{C}, 425-435^{\circ} \mathrm{C}, 455-465^{\circ} \mathrm{C}, 465-475^{\circ} \mathrm{C}$, the bonding time is $60 \mathrm{~S}$. The damaged area and the residual silicon area of Glass surface in those figure is occurrence of bonded area. The glass surface without damage area is no occurrence of bonded area. According to the calculation formula of void fraction (1-1), bonded to the void ratio was calculated at different temperatures, and the results in the following table.

Table 1. Bonding void fraction of $395^{\circ} \mathrm{C}-485^{\circ} \mathrm{C}$ temperature

\begin{tabular}{ccccccc}
\hline Sample & Area $\mathrm{mm}^{2}$ & Pressure $\mathrm{N}$ & Time $\mathrm{S}$ & Temperature $^{\circ} \mathrm{C}$ & Voltage $\mathrm{V}$ & Void fraction \% \\
\hline 1 & 16 & 1 & 60 & $395-405$ & 1200 & $\geqq 95$ \\
2 & 16 & 1 & 60 & $405-415$ & 1200 & 79.17 \\
3 & 16 & 1 & 60 & $415-425$ & 1200 & 43.75 \\
4 & 16 & 1 & 60 & $425-435$ & 1200 & 33.33 \\
5 & 16 & 1 & 60 & $435-445$ & 1200 & 16.67 \\
6 & 16 & 1 & 60 & $445-455$ & 1200 & $\leqq 5$ \\
7 & 16 & 1 & 60 & $455-465$ & 1200 & $\leqq 5$ \\
8 & 16 & 1 & 60 & $465-475$ & 1200 & $\leqq 5$ \\
9 & 16 & 1 & 60 & $475-485$ & 1200 & $\leqq 5$ \\
\hline
\end{tabular}

Drawing porosity distribution by experimental data in Table 1, as viewed in Figure 5, it shows that as the porosity will gradually increased as the temperature decreases, reaching at $445-455^{\circ} \mathrm{C} 5 \%$ or less (indicating bonded area has reached $95 \%$ above, the bonding of good quality), as the temperature continues to rise, porosity remains below $5 \%$.

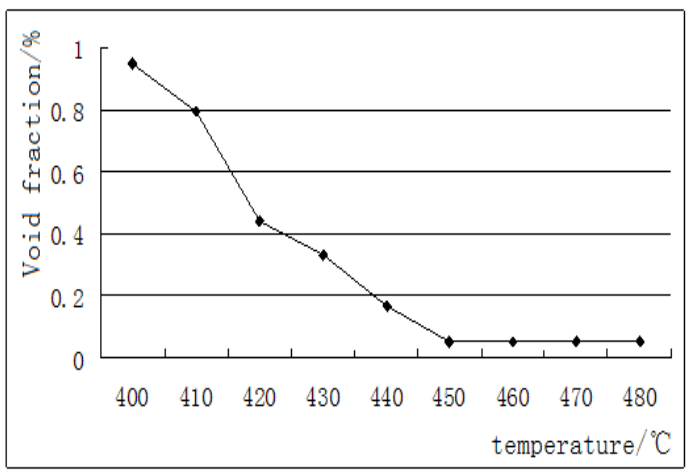

Figure 5. Distribution diagram of $395^{\circ} \mathrm{C}-485^{\circ} \mathrm{C}$ temperature bonding void fraction

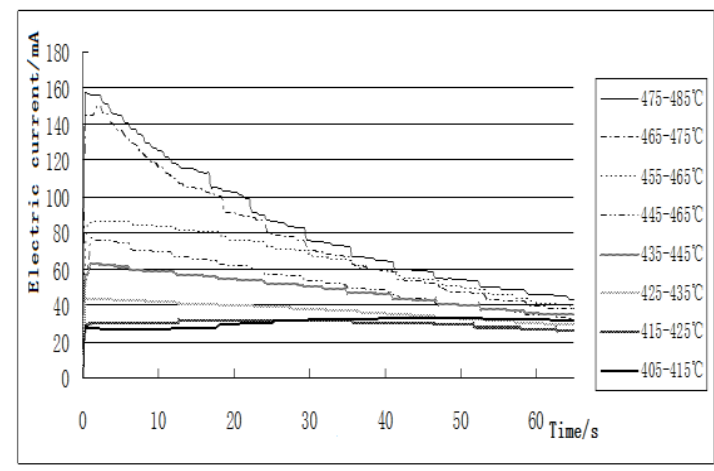

Figure 6. Distribution diagram of $405^{\circ} \mathrm{C}-485^{\circ} \mathrm{C}$ temperature bonding electric current

Observation of the bonding current distribution at different temperatures Figure 6, as the temperature increases, the higher the temperature the greater the initial current bond.When bonding begins, the current changes, but eventually dropped to about 20-40mA, surface bonding is completed. By analyzing the porosity $\leqq 5 \%$ of the current data discovery, improve quality requires a minimum of stability current $70 \mathrm{~mA}$, bonding quality will be increased.

\subsection{Effect of the Bonding Material Specifications for Bonding Quality}

Since the bonding of silicon and glass used in the specifications are very small, restricted package structure, bonding the silicon wafer size also have an impact on the quality of the package.In order to explore the relationship between material specifications for porosity, different sizes of silicon wafers were bonded to the test, the test results in the following table.

Table 2. Bonding void fraction of different specifications of silicon wafer

\begin{tabular}{ccccccc}
\hline Sample & Area $\mathrm{mm}^{2}$ & Pressure $\mathrm{N}$ & Time $\mathrm{s}$ & Temperature $^{\circ} \mathrm{C}$ & Voltage $\mathrm{V}$ & Void fraction \% \\
\hline 1 & 8 & 1 & 60 & $445-455$ & 1200 & 50 \\
2 & 6.5 & 1 & 60 & $445-455$ & 1200 & 66.67 \\
3 & 6 & 1 & 60 & $445-455$ & 1200 & 83.33 \\
4 & 4.5 & 1 & $60 \mathrm{~s}$ & $445-455$ & 1200 & $\geqq 95$ \\
\hline
\end{tabular}

TELKOMNIKA Vol. 16, No. 2, November 2015: 291 - 295 
As can be seen from the Table 2, the size of bonding silicon wafer so closely related to void fraction. When the silicon-bonded area gradually decreases, the void fraction increases, the bonding quality decreased. Because the pressure plate area for applying the bonding pressure is far greater than the silicon area, when the silicon area is $4.5 \mathrm{~mm}$, void ratio as high as $95 \%$, the bonding quality is low.

\subsection{Effect of Bonding Time for Bonding Quality}

In order to study the influence of bonding time on the bonding results, set the bond voltage $1200 \mathrm{~V}$, the temperature of $445-455^{\circ} \mathrm{C}$, the contrast test of bonding time $20 \mathrm{~s}, 30 \mathrm{~s}, 40 \mathrm{~s}$, $50 \mathrm{~s}, 60 \mathrm{~s}, 120 \mathrm{~s}, 180 \mathrm{~s}$. From the void fraction distribution curve can be seen from the Table 4, bonding time is larger than $60 \mathrm{~s}$, bonding voids ratio is less than $5 \%$, the bonding quality is better. Therefore, in order to improve the bonding efficiency, reduce the bonding energy consumption, bonding time is generally controlled at 60 s.

Table 3. Bonding void fraction of $20 \mathrm{~s}-180 \mathrm{~s}$

\begin{tabular}{ccccccc}
\hline Sample & ${\text { Area } \mathrm{mm}^{2}}^{2}$ & Pressure N & Time s & Temperature $^{\circ} \mathrm{C}$ & Voltage V & Void fraction \% \\
\hline 1 & 16 & 1 & 20 & $445-455$ & 1200 & 18.75 \\
2 & 16 & 1 & 30 & $445-455$ & 1200 & 8.33 \\
3 & 16 & 1 & 40 & $445-455$ & 1200 & 7.29 \\
4 & 16 & 1 & 50 & $445-455$ & 1200 & 6.25 \\
5 & 16 & 1 & 60 & $445-455$ & 1200 & $\leqq 5$ \\
6 & 16 & 1 & 120 & $445-455$ & 1200 & $\leqq 5$ \\
7 & 16 & 1 & 180 & $445-455$ & 1200 & $\leqq 5$ \\
\hline
\end{tabular}

\section{Conclusion}

Tests showed that the use of MEMS package test platform can improve the accuracy of the manipulation of the packaging process, the accurate control of the bonding temperature, bonding time, and the pulse voltage.Quality bonding depends on the bonding temperature, material specifications, bonding time, and craftsmanship. Tests showed that the applied voltage of $1200 \mathrm{~V}$, the bonding time is $60 \mathrm{~s}$, the bonding temperature of $445^{\circ} \mathrm{C}-485^{\circ} \mathrm{C}$, the void fraction of $5 \%$ or less can achieve good bonding quality. The silicon wafer bonding specifications smaller, the greater of the void fraction. Bond length of time has little effect on the bonding quality. After reaching the minimum stable current bond, bonded completed within time soon.Through theoretical analysis and experimental research confirms that control bonding temperature and bonding time can improve the efficiency of industrial production.

\section{References}

[1] Liu XR, Hu Z, Zou XQ. A Practical SDB technology for high voltage devices. Microelectronics. 1994; 24(3):10-12.

[2] Li H. Study on glass-ceramics of low-temperature anodic bonding for application in MEMS. Wuhan, Wuhan University of Technology. 2008: 50-130.

[3] Chen YH, Shi ZG, Zheng YB, et al. Effects of different bonding temperatures on the low temperature si-si eutectic bonding. Microelectronics Technology. 2013; 50(9).

[4] George Wallis, Daniel I Pomerantz. Field assisted glass-metal sealing. Journal of Applied Physics. 1969; 40: 3946.

[5] Zhang Z, Wang XF, Wang YZ, et al. Study on Au-Si bonding of wafer level MEMS vacuum packaging. Electronics \& Packaging. 2011; 11(1): 1-4.

[6] Liu YL, Wang X, Zhang WZ, et al. Study of new way about si/si bonding. Chinese journal of rare metals. 2000; 24(1): 16-24.

[7] Anish Saran. Anodic bonding of optical fibers-to-silicon for integrating MEMS devices and optical fibers. Journal of Micromechanics and Microengineering. 2003; 13: 346-351.

[8] Lin ZX, Wang SG, Liu Q, et al. Anodic bonding of glass-silicon-glass three-layer structure with Si3N4 thin film. Transducer and Microsystem Technologies. 2013; 32(8): 63-70. 